\title{
Optimization of interbaric surface parameters taking into account the radial pulsation of the plant mass in the threshing space
}

\author{
Oksana Pyatnitzkaya ${ }^{1}$, Elena Fisunova ${ }^{1}$, Tatyana Lavrenova ${ }^{1,{ }^{*}}$, Olga Baryshnikova $^{1}$ and \\ Danil Filatov ${ }^{1}$ \\ ${ }^{1}$ Don State Technical University, 1, Gagarin square, 344003, Rostov-on-Don, Russia
}

\begin{abstract}
The article deals with the study of the penetration of stems and free grains into the interdigital spaces. The parameters of the interbearing surface of the plant mass in the threshing space are analyzed.
\end{abstract}

\section{Introduction}

The closed drum separates grain better [1]. However, it is more damage the straw and is less addictive ability in the classical rod and slatted performance concave.

In this article it is shown that in a serial threshing drum [2] transition from an angle of inclination of $30^{\circ}$ to an angle of $56^{\circ}$ is admissible (Fig. 1).

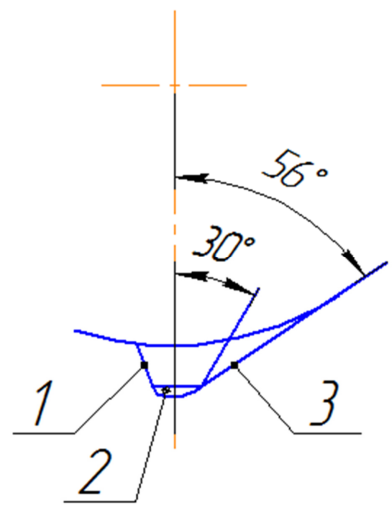

Fig. 1. Changing the position of the frontal surface of henhead on the condition of conservation gripping ability of threshing drum (1-henhead; 2-whip; 3-reflective shield).

The latter is found from the condition of preserving the exciting ability of the threshing drum at the input of the concussion. 2.

The scheme of the interbearing reflecting surface of a similar drum is presented in Fig.

*Corresponding author: bys_ka87@mail.ru 


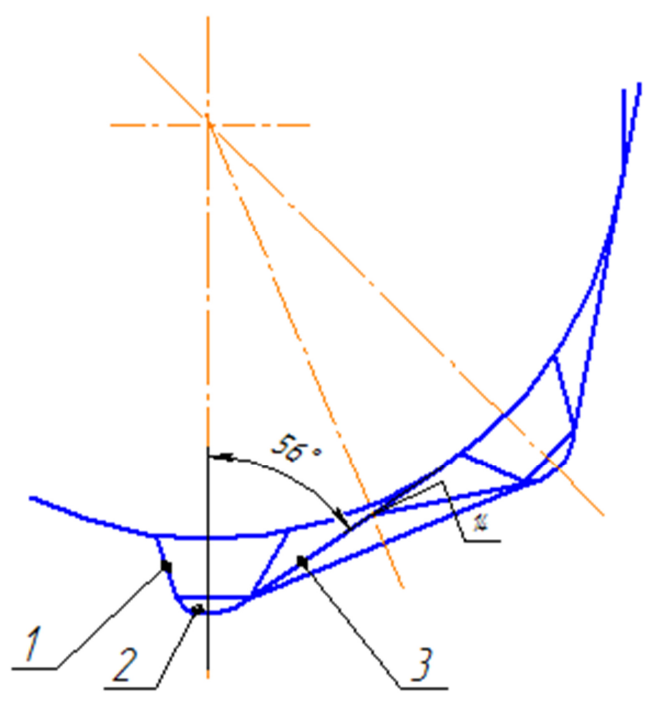

Fig. 2. Change interbearing space of the drum closed execution on the condition of conservation gripping ability of the drum: 1 henhead; 2 whip; 3 - interbearing reflective surface.

Such a drum (Fig. 3) threshing unit intensive action has shown relatively high results on the degree of separation of the grain concave. However, damage of the stem mass during threshing remained at or even higher than that of the serial unit [1].

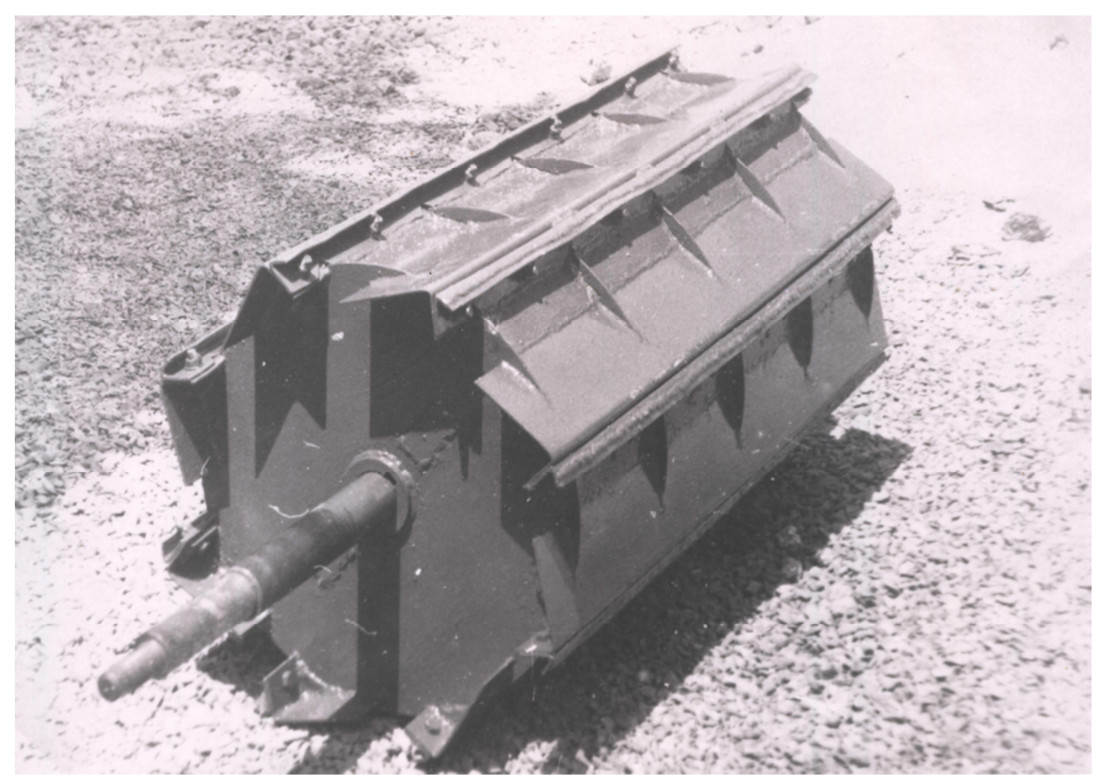

Fig. 3. The threshing drum of the closed execution with the bent interbearing reflecting surfaces for the combine harvester SK-5 "Niva" (by Cousin G.A.).

It has been experimentally established [3] that when the grain mass moves in the threshing space, the so-called "radial pulsation" of the straw flow is observed (Fig. 4), which was associated until recently exclusively with the compression of the bread mass with whips. 


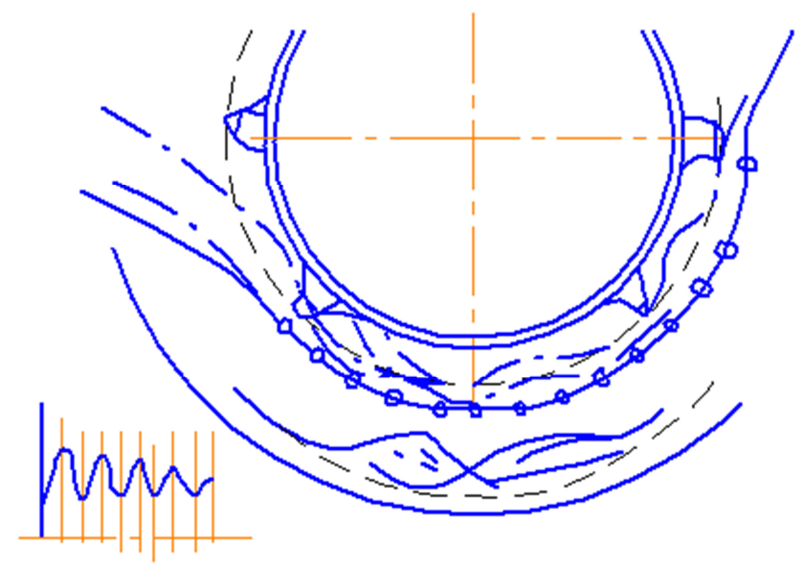

Fig. 4. Radial pulsation of the bread mass in the threshing space (according to Vasilenko I. F.).

A more complete explanation of this phenomenon is given in [1]. The main reason for this behavior of the grain flow in the threshing space along during the pressure of the whips is the inhibition of discrete stems by radiallyoriented whip bars[4] . The ends of the stems on their path to the exit of the threshing space rested in a strap, and move slow down because of this interbearing spaces. A clear confirmation of the stem behavior is a picture of hammering in threshing apparatus (Fig. 5).

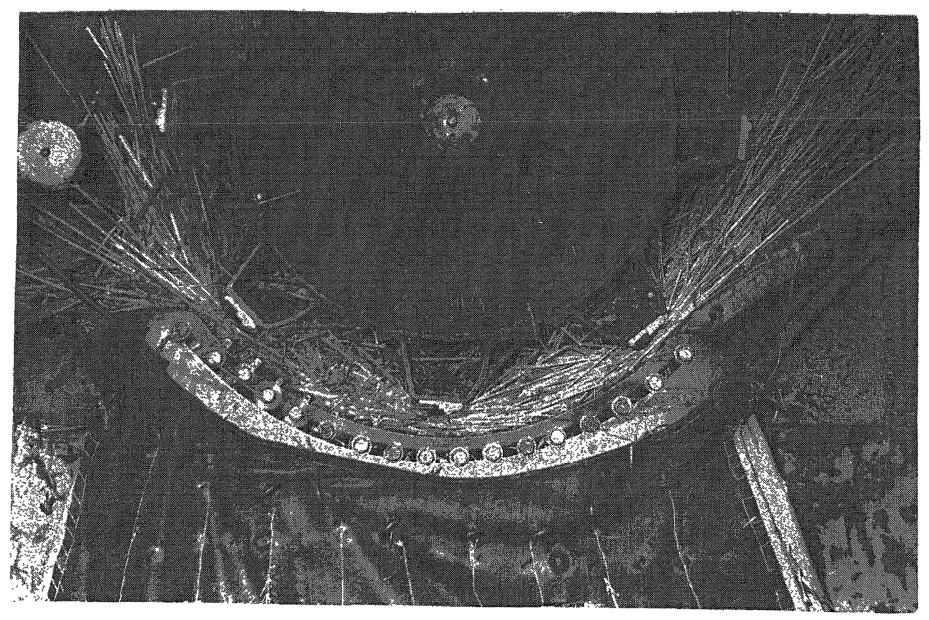

Fig. 5. Hammering of threshing machine in combine harvester SK-5 "Niva".

The volume and shape of the interbearing space depends on whether the stem is damaged by the incoming scourge, if it does not" fit " into the interbearing window, or the whip will have a minimal impact on the integrity of the stem mass[5].

To search for the shape and size of the interbearing space we should proceed not only from the preservation of the exciting ability of whips, but also from the condition of preserving the integrity of the stems when they bulge.

To determine the rational shape and size of the reflecting interdigital surface[6], we have solved the problem of the stem bulging as an elastic rod under the influence of a whip that compresses the stem in the longitudinal direction and the bar as a braking element. The scheme of such interaction (in the front part of the threshing space-where the stem is not yet deformed, and therefore can be considered as a rectilinear elastic rod) is presented in Fig. 6 . 
The diagram shows a stem length of $1=25.4 \mathrm{~cm}$ (the distance between adjacent whips threshing drum combine "don-1500") with hinged ends. Moreover, one of the ends has the freedom to move along the axis of the stem[7]. We believe that in the process of movement, the right end of the stem loses mobility, pinching in the zone of interaction of elements of the "beach-stem-plank" system[8]. The reason for pinching is the difference in the coefficients of friction of the stem on the stem and on the steel.

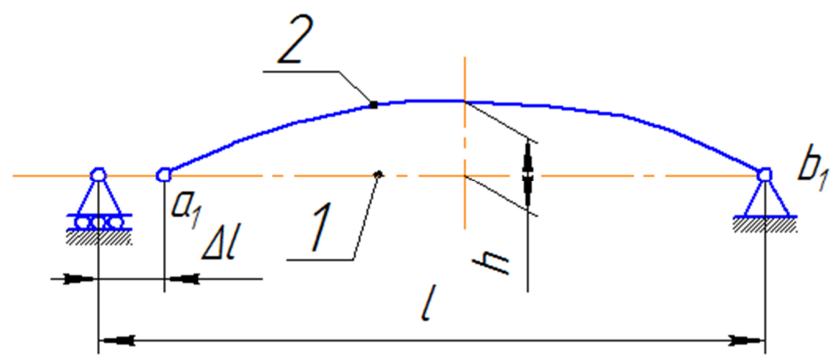

Fig. 6. Scheme to determine the boom of the stem bugling (1-stem before bending; 2-stem after bending).

The duration of braking corresponding to the time of immobility of the right end can be determined by the formula:

$$
t=\frac{b}{V_{b}}
$$

where $b$ - is the width of the whip; $V_{b}$ is the speed of the whip.

The left end of the stem continues to move at the speed of $V_{c}$ flow.

The flow rate of the stem mass at the input section of the concave in the threshing apparatus of the combine SK-5 "Niva" varies within 3,2..6,1 $\mathrm{m} / \mathrm{s}$ [4]. Assuming that in the same range will vary the flow rate in the harvester "don-1500", take to use the average speed value $4,65 \mathrm{~m} / \mathrm{s}$.

During time $t$ the input end of the stem will shift the distance:

$$
\Delta l=V_{c} t
$$

In this case, the bending of the stem with such a fixation of the ends will occur along the sinusoid. The equation of the elastic line of the stem in this case is:

$$
y=h \sin \frac{\pi x}{l}
$$

where $h$ - is the deflection (buckling) arrow of the stem.

The length of the arch of the curved stem can be found from the expression:

$$
S=\int_{a_{I}}^{b_{I}} \sqrt{1+\left(\frac{d y}{d x}\right)^{2}} d x
$$

Or after differentiation by formula:

$$
S=\int_{a_{I}}^{b_{I}} \sqrt{1+\left[\frac{\pi h}{l} \cos \left(\frac{\pi x}{l}\right)\right]^{2}} \cdot d x
$$


In expression (5), $S$ can be assumed to be $l$, assuming that the length of the stem does not change as a result of bending[9]. Then, from the expression (5) transformed in this way, we can find the value of the deflection boom $\mathrm{h}$ of the rod, which is the determining parameter of the interbearing reflecting surface (along with the shaping curve - sinusoid).

One of the numerical integration methods can be used to determine the arc length[10]. Such in the first approximation can be "method rectangles."

Find the value of expression (5) with the following input data:

$$
\mathrm{h}=0,027 \mathrm{~m} ; \mathrm{l}=0,254 \mathrm{~m} ; \mathrm{V}_{\mathrm{b}}=30 \mathrm{~m} / \mathrm{s} ; \mathrm{V}_{\mathrm{c}}=4,65 \mathrm{~m} / \mathrm{s} ; \mathrm{b}=0,045 \mathrm{~m}
$$

According to expression (1):

$$
t=\frac{b}{V_{b}}=\frac{0,045}{30}=0,0015 c .
$$

From expression (2) we find:

$$
\Delta \mathrm{l}=\mathrm{V}_{\mathrm{c}} \mathrm{t}=4,65 \cdot 0,0015=0,007 \mathrm{~m} .
$$

Then we can find the limits of integration:

$$
\mathrm{a}_{\mathrm{I}}=0, \mathrm{~b}_{\mathrm{I}}=1-\Delta \mathrm{l}=0,254-0,007=0,247 \mathrm{~m} \text {. }
$$

After substitution of the found and initial values in expression (5) we get:

$$
S=\int_{0}^{0,2235} \sqrt{1+\left(\frac{3,14 \cdot 0,03}{0,2235} \cdot \cos \left(\frac{3,14 \cdot x}{0,2235}\right)\right)^{2}} \cdot d x .
$$

Divide the interval $\left[\mathrm{a}_{\mathrm{I}}, \mathrm{b}_{\mathrm{I}}\right]$ into 10 equal parts, we obtain a sampling step $\Delta \mathrm{x}=0,0247 \mathrm{~m}$.

Next, we calculate the value of the integrand $(5$,$) when x$ changes in the range $(0 \ldots$ 0,247) $\mathrm{m}$.

By choosing the value $h$, it is possible to achieve equality of the calculated value of the arc length $S$ to the initial value 1 of the stem with the necessary accuracy [11]. As a result of a number of refinements, we obtain the actual value of $h_{f}=0,027 \mathrm{~m}$.

Optimization of the parameters for the rational interbearing reflecting surface is carried out according to the scheme in Fig. 7.

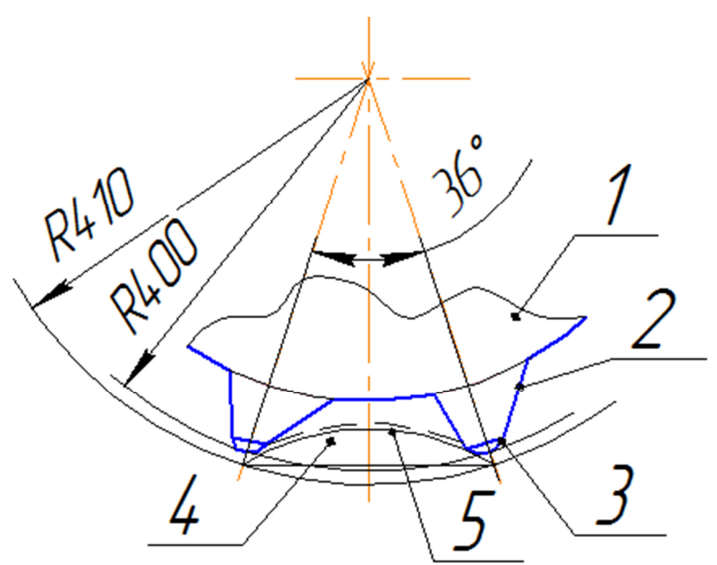

Fig. 7. For the calculation of the interbearing surface parameters: 1 - drum; 2 - henhead; 3 whip; 4 bugling curve; 5 - equidistant curve. 
The distance between adjacent whips is $0,254 \mathrm{~m}$. "Boom bugling" is $h_{f}=0,027 \mathrm{~m}$. The circumference of the threshing drum and concave are concentric. Curve 4 is constructed according to equation (5). Curve (5) equidistant curve 4 and may represent a curve profile interbearing surface. At the Fig. 7 the arc of a sine wave is approximated by the arc of a circle[12].

\section{Summary}

On the basis of the conducted researches of penetration of stalks and free grains into interbearing spaces it is possible to conclude the following:

1. Bugling of stems in the interbearing space in the result of inhibition of the stem final element in the area of "whip- bar" and backwater from the incoming mass occurs along a curve (sine wave) from the deflection 25... $35 \mathrm{~mm}$ (Harvester "Don-1500"). The penetration of free grains into the interbearing spaces occurs as a result of reflection from the concave at a speed of up to $20 \mathrm{~m} / \mathrm{s}$, which allows to be the possibility of collision with the descending branch of the reflection surface. The parameters of the reflecting interbearing surface should take into account these two circumstances.

2. Ascending branch of the interbearing reflecting surface can be approximated by a plane with a radial direction an angle equal to $60 . .70$ degrees.

3 . The descending branch of the reflecting interbearing surface can be approximated by a plane with a tangential angle of 40 degrees.

4. Increasing the speed of rotation in the threshing drum for critical values for the threshing machine with a closed drum is a real factor in the intensification of the threshing process[13].

5. A significant contribution to the increase of the separating action of the threshing machine with a drum of closed execution with increasing of whip speed is made by the reducing phenomenon of the grain recovery coefficient on impact [14].

6. Increasing the efficiency of the threshing machine with a closed drum can be implemented in two versions:

- by reducing of the grain crushing at the same speed and a low value of the normal component of the shock pulse;

- by increasing of the separation and grain grinding at an increased speed of rotation of the drum and the allowable level of damage [15].

\section{References}

1. G.A. Kuzin, Intensification of threshing and separation processes in threshing machines of combine harvesters|Scientific work of Doctor of Sciences (Rostov-on-don, 2010)

2. V.D. Obrezanov, Investigation of input parameters and interbearing space more or less stable threshing machine. Scien. W. of Ph. D. (Rostov-on-don, 2011)

3. I.F. Vasilenko, Grain combines of the USSR and foreign countries (Agriculture, Moscow, 2010)

4. O.P. Cherednichenko, Optimization of input parameters for concave of threshing machine harvester. Dis. Ph. D. (Rostov-on-don, 2012)

5. A. Sewell, Journal of Agricultural Engineering Research 46, 207-217 (1990)

6. A. Khan, Annals of Agrarian Science 14(2), 25-34 (2016)

7. W. Anderson, R. Seager, W. Baethgen, M. Cane, Agricultural and Forest Meteorology 262, 298-309 (2018) 
8. C. Lizana, S. Hess, D. Calderini, Agricultural and Forest Meteorology 149(11), $1964-$ 1974 (2009)

9. K. Chenu, J. Roy Porter, P. Martre, B. Basso, S. Asseng, Trends in Plant Science 22, 472-490 (2017)

10. M. Abinasa, A. Ayana, G. Bultosa, Afr. J. Agric. Res. 6(17), 3972e3979 (2011) http://www. academicjournals.org/AJAR

11. R. Raghuwanshi, Opportunities and challenges to sustainable agriculture in India NEBIO 3(2), 78-86 (2012)

12. M. Akhalkatsi, J. Ekhvaia, Z. Asanidze Perspectives on Nature Conservation patterns Pressures and Prospects in Tech. Rijeka, 51-92 (2012) http://dx.doi.org/10.5772/30286

13. M. Akhalkatsi, A. Otte, N. Togonidze, T. Bragvadze, L. Mazanishvili, Annals of Agrarian Science 15(1), 11-16 (2017)

14. C. Guo, Y. Tang, J. Lu, Y. Zhu, Y. Tian, Agricultural and Forest Meteorology 272273, 69-80 (2019)

15. C. Rosenzweig, J. Jones, J. Hatfield, A. Ruane, J. Winter, Agricultural and Forest Meteorology 170, 166-182 (2013) 